Original Research Article

\title{
A survey to assess the knowledge of adverse drug reactions and pharmacovigilance practices among undergraduate medical students, interns and postgraduate students in a tertiary care hospital
}

\author{
Mamatha N., Reshma Nadaf*
}

Department of Pharmacology, Karnataka Institute of Medical Sciences, Hubballi, Karnataka, India

Received: 12 July 2017

Accepted: 05 August 2017

*Correspondence to:

Dr. Reshma Nadaf,

Email: dr_reshmanadaf@

yahoo.com

Copyright: (C) the author(s), publisher and licensee Medip Academy. This is an openaccess article distributed under the terms of the Creative Commons Attribution NonCommercial License, which permits unrestricted noncommercial use, distribution, and reproduction in any medium, provided the original work is properly cited.

\begin{abstract}
Background: The objective of the study was to evaluate the knowledge and attitude towards pharmacovigilance and adverse drug reaction (ADR) reporting among the undergraduates, interns and postgraduate students.

Methods: This was a cross sectional study done among the undergraduates, interns and post graduate medical students at Karnataka Institute of Medical Sciences, Hubballi using a pre-validated questionnaire that included 20 questions to evaluate the participants knowledge and perception of ADR and pharmacovigilance. The questionnaire was distributed to the participants $(n=606)$ after taking their informed consent. The data was compiled and evaluated as percentages.

Results: About $52 \%$ of the participants were aware of pharmacovigilance and $38.7 \%$ knew about the purpose of pharmacovigilance programme of India. 51\% of the participants have experienced ADRs during their professional practice out of which $23 \%$ have reported to the pharmacovigilance centre. The most common barrier for under-reporting was lack of time to report ADR among $34 \%$ of the participants. $31 \%$ of the participants felt that managing patient was more important than reporting ADRs. $29 \%$ of the participants gave the reason as lack of access to ADR reporting forms. $25 \%$ of the participants had difficulty to decide whether ADR has occurred or not.

Conclusions: Our study strongly suggests a greater need to create an awareness among undergraduate medical students, interns and postgraduate students to improve the reporting of ADRs.
\end{abstract}

Keywords: ADR, Interns, Pharmacovigilance, Postgraduates, Undergraduate medical students

\section{INTRODUCTION}

According to WHO Adverse drug reaction is defined as "Any response to drug which is noxious or unintended and occurs at a dose normally used in man for prophylaxis, diagnosis or treatment of diseases or for modification of physiological function". 1

Pharmacovigilance is defined as "the science and activities relating to the detection, assessment, understanding and prevention of adverse effects or any other drug related problems."
Spontaneous reporting of ADRs has contributed significantly to the success of pharmacovigilance.

It is estimated that only $6-10 \%$ of adverse drug reactions are reported. ${ }^{2}$

Despite the efforts of established ADR monitoring centers in many hospitals and the presence of a large number of tertiary care facilities, pharmacovigilance is still in its infancy. ${ }^{3}$ 
Under-reporting is a major limitation for drug safety surveillance.

The ultimate focus narrows down to health care professionals spontaneous reporting of ADRs, for improving the reporting rates. ${ }^{3}$

Assessment of awareness of pharmacovigilance among health care professionals is said to be important to find the reason for under-reporting of adverse drug reactions. ${ }^{4}$

Hence, the present study was done to evaluate the knowledge and attitude towards pharmacovigilance and adverse drug reaction (ADR) reporting among the undergraduates, interns and postgraduate students and to analyze the barriers involved in non reporting of suspected ADRs.

\section{METHODS}

This was a cross-sectional study done among undergraduates, interns and postgraduate medical students for a period of 1 month at Karnataka Institute of Medical Sciences, Hubballi.

A questionnaire containing 20 questions was designed and validated to evaluate the participants knowledge and perception on ADR and pharmacovigilance.

Total 606 questionnaires were prepared and distributed to 606 subjects. Out of 606 subjects 136 were $2^{\text {nd }}$ year, 128 were $3^{\text {rd }}$ year, 120 final year medical students, 84 of them were internship students and 138 postgraduate medical students.

After taking their informed consent, the participants were personally briefed about the questionnaire and they were requested to return the duly filled forms.

The participants were given 15 minutes to answer the questionnaire and they were not allowed to consult anyone or internet during that time.
They could maintain anonymity with regard to their names, but had to write their designations.

The data was analyzed question-wise and their percentage value was calculated with the help of Microsoft Excel Spread sheet in MS office 2007.

\section{Inclusion criteria}

- $\quad 2^{\text {nd }}$ year, $3^{\text {rd }}$ year and final year MBBS students

- Interns and postgraduate students.

\section{Exclusion criteria}

- $\quad 1^{\text {st }}$ year MBBS students

- Those not willing to participate in the study.

\section{RESULTS}

Out of 606 participants, 136 were $2^{\text {nd }}$ year, 128 were $3^{\text {rd }}$ year, 120 final year medical students, 84 of them were internship students and 138 postgraduate medical students. The respondents were in the age group of 19- 28 years. $52 \%$ of the participants knew what is pharmacovigilance, $38.7 \%$ of the participants knew about the purpose of pharmacovigilance.

$69 \%$ agreed that all the health care professionals like (doctors, nurses, pharmacists) are responsible for reporting ADR's.

Results of evaluation of knowledge regarding ADR reporting is shown in the Table 1 .

The awareness about pharmacovigilance among the participants is shown in Figure 1.

$22 \%$ of $2^{\text {nd }}$ year, $17 \%$ of $3^{\text {rd }}$ year, $41 \%$ of final year students, $17 \%$ of interns and $10 \%$ of postgraduates were aware that a serious adverse event in India should be reported within 15 days to the regulatory body.

Table 1: Evaluation of knowledge regarding ADR reporting.

\begin{tabular}{|c|c|c|c|c|c|c|c|c|c|c|c|}
\hline \multirow{2}{*}{ No. } & \multirow{2}{*}{ Questions } & \multicolumn{2}{|c|}{$2^{\text {nd }}$ year } & \multicolumn{2}{|c|}{$3^{\text {rd }}$ year } & \multicolumn{2}{|c|}{$4^{\text {th }}$ year } & \multicolumn{2}{|c|}{ Interns } & \multicolumn{2}{|c|}{ Postgraduates } \\
\hline & & Yes & No & Yes & No & Yes & No & Yes & No & Yes & No \\
\hline 1 & $\begin{array}{l}\text { Are you aware of existence of } \\
\text { National Pharmacovigilance } \\
\text { programme of India (PvPI)? }\end{array}$ & $80 \%$ & $20 \%$ & $64 \%$ & $36 \%$ & $65 \%$ & $35 \%$ & $72 \%$ & $28 \%$ & $68 \%$ & $32 \%$ \\
\hline 2 & $\begin{array}{l}\text { Which one of the following is } \\
\text { the 'WHO online database' for } \\
\text { reporting ADRs? } \\
\text { Right Ans: vigibase }\end{array}$ & $44 \%$ & $56 \%$ & $46 \%$ & $54 \%$ & $50 \%$ & $50 \%$ & $59 \%$ & $41 \%$ & $57 \%$ & $43 \%$ \\
\hline 3 & $\begin{array}{l}\text { Which one of the following } \\
\text { scales is most commonly used } \\
\text { to establish the causality of an } \\
\text { ADR? } \\
\text { Right ans: Naranjo algorithm }\end{array}$ & $28 \%$ & $72 \%$ & $30 \%$ & $70 \%$ & $41 \%$ & $59 \%$ & $40 \%$ & $60 \%$ & $57 \%$ & $43 \%$ \\
\hline
\end{tabular}




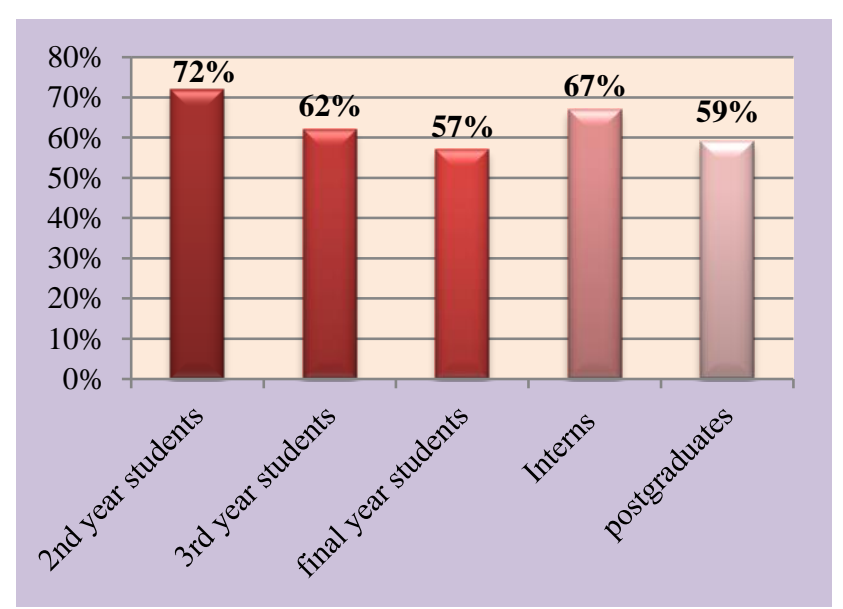

Figure 1: Awareness about pharmacovigilance.

$32 \%$ of the participants were aware of naranjo algorithm as the most commonly used scale to establish the causality of an ADR.

$42 \%$ of the participants were aware of vigibase as the 'WHO online database' for reporting ADRs and 49\% considered reporting ADR as a professional obligation.
$75 \%$ of the participants agreed that pharmacovigilance should be taught in detail to all the healthcare professionals. Results of practices towards ADR reporting is shown in Table 2.

Opinion about establishing ADR monitoring centre is depicted in Figure 2.

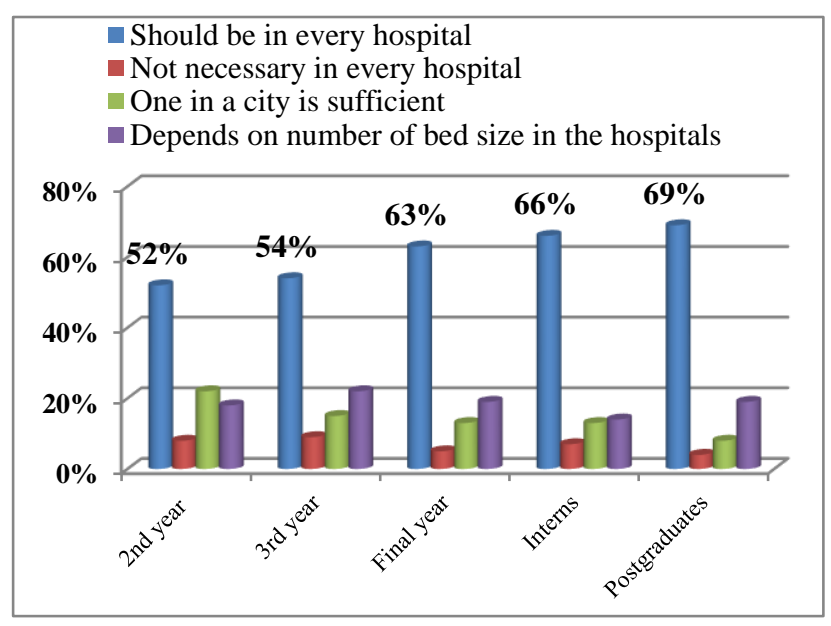

Figure 2: Opinion about establishing ADR monitoring centre.

Table 2: Results of practices towards ADR reporting.

\begin{tabular}{|c|c|c|c|c|c|c|c|c|c|c|c|}
\hline \multirow{2}{*}{ No. } & \multirow{2}{*}{ Questions } & \multicolumn{2}{|c|}{$2^{\text {nd }}$ year } & \multicolumn{2}{|c|}{$3^{\text {rd }}$ year } & \multicolumn{2}{|c|}{$4^{\text {th }}$ year } & \multicolumn{2}{|c|}{ Interns } & \multicolumn{2}{|c|}{ Postgraduates } \\
\hline & & Yes & No & Yes & No & Yes & No & Yes & No & Yes & No \\
\hline 1 & $\begin{array}{l}\text { Do you think reporting of adverse } \\
\text { reaction is necessary? }\end{array}$ & $90 \%$ & $10 \%$ & $96 \%$ & $4 \%$ & $90 \%$ & $10 \%$ & $94 \%$ & $6 \%$ & $90 \%$ & $10 \%$ \\
\hline 2 & $\begin{array}{l}\text { Have you ever experienced ADR in } \\
\text { your patient during your } \\
\text { professional practice? }\end{array}$ & $41 \%$ & $59 \%$ & $49 \%$ & $51 \%$ & $54 \%$ & $46 \%$ & $50 \%$ & $50 \%$ & $64 \%$ & $36 \%$ \\
\hline 3 & Have you seen ADR reporting form & $78 \%$ & $22 \%$ & $67 \%$ & $33 \%$ & $53 \%$ & $47 \%$ & $55 \%$ & $45 \%$ & $39 \%$ & $61 \%$ \\
\hline 4 & $\begin{array}{l}\text { Have you ever reported ADR to } \\
\text { pharmacovigilance centre }\end{array}$ & $17 \%$ & $83 \%$ & $28 \%$ & $72 \%$ & $20 \%$ & $80 \%$ & $25 \%$ & $75 \%$ & $24 \%$ & $76 \%$ \\
\hline
\end{tabular}

- Lack of time to report ADR

- Managing patient more important than reporting

Lack of access to ADR forms

Difficult to decide whether ADR has occurred or not

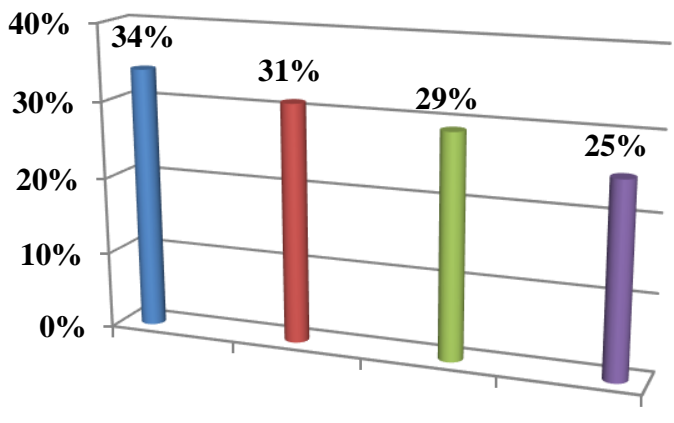

Figure 3: The most common barriers for under reporting as per our study were as follows.
The most common barriers for under reporting as per our study is shown in Figure 3.

\section{DISCUSSION}

This study evaluates the knowledge, attitude and practice of ADR reporting among undergraduates, interns and postgraduates and finding out the reasons for underreporting. Under-reporting of ADRs is a universal phenomenon that exists as an inherent weakness of the current voluntary reporting schemes. ${ }^{5}$ In our study only 20 $\%$ of the participants have reported ADR to the pharmacovigilance centre.

Our results show that the awareness towards ADR reporting is only $39 \% .52 \%$ of the participants knew what is pharmacovigilance, and only $38.7 \%$ of the participants 
knew the purpose of pharmacovigilance. On studying the attitude of participants to report ADRs, 92.2\% of them thought reporting of adverse drug reaction was necessary. $92.07 \%$ were in favour that it should be taught in detail to all healthcare professionals.

According to a study conducted by Thomas TM et al, 75\% (45) of respondents were aware of the existence of suspected ADR reporting system in India; however, only 7 out of 60 respondents $(11.7 \%)$ were aware about regional center of ADR reporting. 69.99\% of respondents were of the opinion that non - availability of reporting forms discouraged them from ADR reporting. Other factors that discouraged them from ADR reporting included busy schedule $(41.6 \%)$, apprehension $(38.33 \%)$, previously known ADRs (38.32\%), inability to diagnose ADR $(34.99 \%){ }^{6}$ Our findings were in agreement with this study.

A study by Thakuria $\mathrm{N}$ et al, showed that $84 \%$ of MBBS students had moderate knowledge about pharmacovigilance and the results were comparable with our study. ${ }^{7}$ According to Sivasadsan $\mathrm{S}$ et al, the results showed that most of the students have positive perception towards ADR reporting. About three fourth of the students agreed that ADR reporting was a professional obligation. ${ }^{8}$ In this study fifty percent of the students agreed that ADR reporting was a professional obligation.

The Drug Controller General of India (DCGI) and Indian Council of Medical Research (ICMR) have put in a lot of effort in setting up many ADR monitoring centers in various parts of India, despite their efforts pharmacovigilance is still in its infant stage in India. ${ }^{6}$

Today, the need for an efficient pharmacovigilance system has been realized more than ever, to ensure the safe use of medicines. Pharmacovigilance is being taught to some extent in theory, but the knowledge on the practical approach is lacking. ${ }^{9}$

ADR reporting can be further improved by educating all healthcare professionals

- By conducting CME's on pharmacovigilance

- Knowledge on PvPI

- $\quad$ Educate to fill the ADR form

- Encourage the healthcare providers to report all suspected ADRs. ${ }^{10}$

\section{CONCLUSION}

This study strongly suggests a greater need to create an awareness among undergraduate medical students, interns and postgraduate students to improve the reporting of ADRs.

Funding: No funding sources Conflict of interest: None declared
Ethical approval: The study was approved by the Institutional Ethics Committee

\section{REFERENCES}

1. Rohilla A, Yadav S. Adverse drug reaction: An overview. International Journal of Pharmacological Research. 2013;3(1):10-2.

2. Kaikade SB, Pise ND. Knowledge and awareness about ADR reporting and pharmacovigilance among medical undergraduates. International Journal of Biomedical Research. 2016;7(5):295-6.

3. Patil AA, Gurav VA, Thorat MB, Walsangikar SD. Survey of pharmacovigilance awareness among health care professionals. International Journal of Pharmacology And Therapeutics. 2014;4(3):31-4.

4. Amancharla MK, Choppara JV, Keelu RK, Kommavarapu P, Kotannagari VV. Study of awareness of pharmacovigilance among health care professionals and medical students attached to a tertiary care hospital in Andhra Pradesh, India. International Journal of Current Medical and Applied Sciences. 2015Jan;5(2):63-7.

5. Kharkar M, Bowalekar S. Knowledge, attitude and perception/practices (KAP) of medical practitioners in India towards adverse drug reaction (ADR) reporting. Perspectives in clinical research. 2012 Jul;3(3):90.

6. Thomas TM, Udaykumar P, Scandashree K. Knowledge, attitude and practice of adverse drug reaction reporting among doctors in a tertiary health care centre in South India. Int J Pharmacol and Clin Sci. 2013;2:82-8.

7. Thakuria N, Deka D, Choudhury D, Ahmed N. A cross sectional study to evaluate the knowledge, attitude and practices of healthcare professionals on pharmacovigilance at Silchar medical college and hospital, Assam, India. Int J Basic Clin Pharmacol. 2016;5:1481-9.

8. Sivasadasan S, Sellappan M. A study on the awareness and attitude towards pharmacovigilance and adverse drug reaction reporting among nursing students in a private university, Malaysia. Int J Curr Pharm Res. 2014;7(1):84-9.

9. Hema NG, Bhuvana KB. Pharmacovigilance: The Extent of Awareness Among the Final Year Students, Interns and Postgraduates in a Government Teaching Hospital. Journal of Clinical and Diagnostic Research. 2012 September;6(7):1248-53.

10. Bharadwaj V, Budania N, Mondal A, Yadav V, Sharma P. A Survey to Assess the Awareness of Adverse Drug Reactions and Pharmacovigilance Practices among Healthcare Professionals in a Tertiary Care Hospital. Int J Med Res Prof. 2016;2(1):134-7.

Cite this article as: Mamatha N, Nadaf R. A survey to assess the knowledge of adverse drug reactions and pharmacovigilance practices among undergraduate medical students, interns and postgraduate students in a tertiary care hospital. Int $\mathrm{J}$ Basic Clin Pharmacol 2017;6:2206-9. 